\title{
Empirical Evaluation of Complex System Interfaces for Power Plant Control Room Using Human Work Interaction Design Framework
}

\author{
Anant Bhaskar Garg ${ }^{1}$ and K.K. Govil ${ }^{2}$ \\ ${ }^{1}$ Centre for Information Technology, \\ College of Engineering Studies, \\ University of Petroleum \& Energy Studies, Dehradun, India \\ ${ }^{2}$ Power Plant Consultant \\ anantgg@yahoo.com
}

\begin{abstract}
This paper first discusses two cognitive science paradigms and then present third approach related to interaction with the world as known as embodied cognition. The focus is to analyze work settings with the help of cognitive work analysis and human work interaction design approaches. The case of power plant control room is discussed and analyzed in the context of human system interactions, work and task analysis. This approach helps in reducing cognitive workload on operator which can result in reduction in errors in managing the control room of the power plant.
\end{abstract}

Keywords: Cognitive Work Analysis, Embodied cognition, Human Work Interaction Design, Power Plant Control Room, Ecological Interface Design.

\section{Introduction}

In the year 1956, two different conferences and seminars gave birth to two new research areas known as Artificial Intelligence and Cognitive Science. They stress that brain functions like a computer that specifies symbols can be processed and manipulated and known as cognitivism. This view that thought is manipulation of abstract symbols, algorithmic computation in the same way as computer does. All meaning arose via correspondences between symbols (words, mental representations) and things in the external world. The mind was seen as a mirror of nature, and human thought as abstract and disembodied. Therefore, in principle, a computer could replace a brain, and in particular computers can do anything that brains can do. But this give rise to symbol grounding problem and unable to explain how we get meaning of objects.

The two main approaches (symbolic and connectionist) study cognition of an individual being but as we live in the world, environment and interaction with others play an important role. This thinking leads to theories of embodied and situated cognition, where cognition is seen as taking place not only in the brain, but also in interaction with the world supported by the body [1], [2]. Moreover, this may suggest that neural 
processes not only generate sensory experiences, but also help in exploratory interaction with the world that guides action or behavior. This paradigm finds applications in various research projects notably robotics, autonomous agents, and interactive interfaces [3], [4]. This requires awareness of the relationship with the world especially work, physical movement, action, and other affective behavior reactions. Everyday human activities include all of above states that we can understand through work analysis, and embodied cognition - both are prominent paradigm in cognitive science. Embodied cognition, CWA, and Cognitive System Engineering (CSE) [5] provide a new framework for Human Work Interaction Design (HWID) research. A more detailed HWID framework is given by [6] (as shown in figure 1).

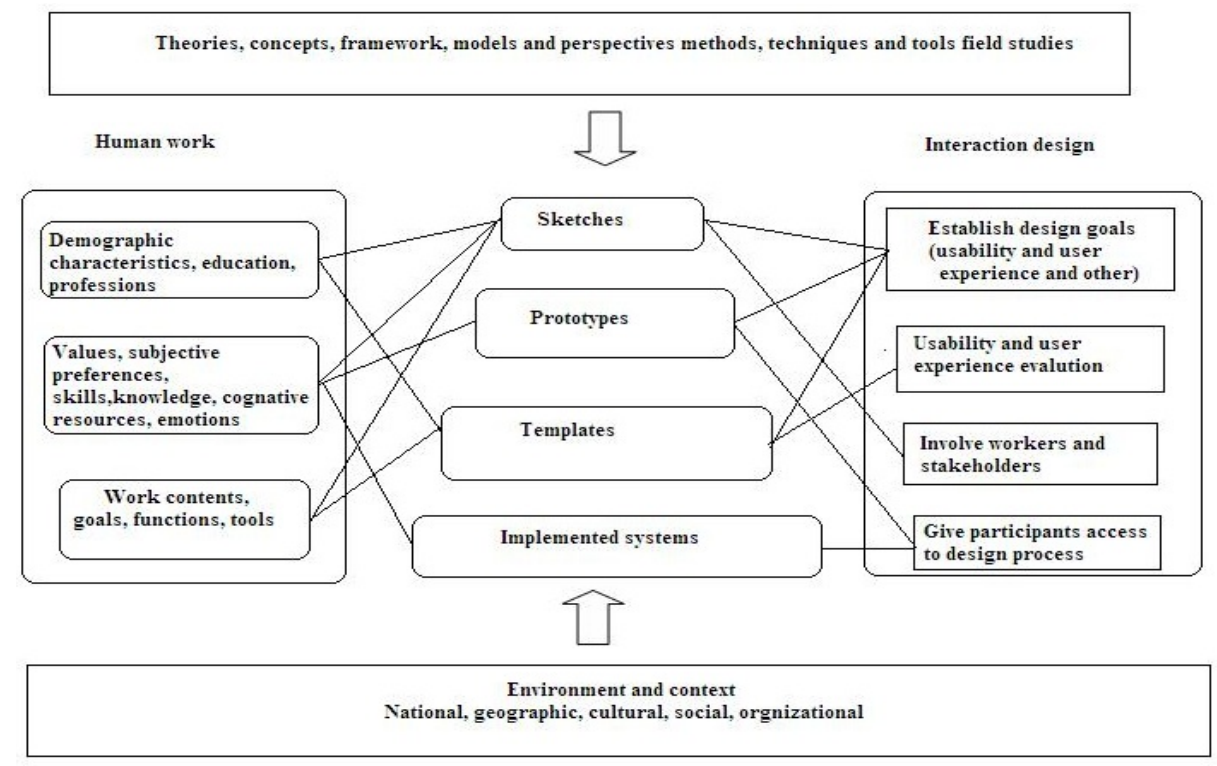

Fig. 1. A Framework of HWID [6]

To represent organizational settings that describe work processes we need to understand role of information and functional demands of the dynamic work environment. Mapping of information to features must show underline semantic structure of the work domain. This require nesting of information which implies meaning inherit in the work processes. For this, we require knowledge and understanding of objects. Objects are those with which we deal in everyday world. How we acquire the meaning and refer to the symbol or sign. Informatics and cognitive science deal with problems representation, semantics of computation and their application to create technology.

\section{HWID Framework for Control Room}

All this depends on perception of objects and conception of object that has been embedded in commonsense discourse. Mental phenomena, spoken \& written language, 
and systems of signs \& codes are intentional. According to Brian Smith, how we represent objects of the world and real-world situation in the computer is the vital point in understanding human functioning. So he says that experience we have with constructing computational (intentional) systems may open a window onto something to which we would not have any access [7]. Therefore, present research will suggest ways to design and develop systems, which are more suitable for varied situations and users.

Above research work is related to field of Man - Machine Interface (MMI) / Human - Computer Interaction (HCI), HWID in particular with the installation and operation of machines in the power plant. Here design of interfaces and interactions with control panel effect working of human operators. Through better-designed interfaces we can increase effectiveness, safety, and decision-making. Thus understanding the work situations and processes are important for improving design of control room and interfaces. It is important that how we could design machines so that they help human in every aspect and they will be their most efficient and effective assistants.

\subsection{Work Study}

To study human interaction with environment for studying power plant control room systems we require the understanding of what we mean by 'information' and flow of information within particular situation. Information is experienced in perception, retained by memory, and manipulated via symbols. Thus, 'information' is central for the exploration of technical, social, and aesthetic bases of human interaction with the world. This provides the framework for our understanding of the underlying patterns of 'information' transmission, storage, and retrieval. Conceptual knowledge of concepts such as ontologies, usability issues, and knowledge management help us to create better systems. Conceptual structures based model assist learner in retrieving, evaluating, and comprehending information through the use of semantic associations. This helps in knowing, how we discover and learn regularities in the environment from the consequences of our actions. How information, communication and technologies (ICT) can best be used for effective and efficient transmission of information to all irrespective of socio-cultural background and abilities? The above analysis is based on some goals and performance measures and their understanding. How interface design can be improved through approaches such as ecological interface design [8]? What are testing methods \& situations that show the effectiveness of the interfaces?

Further, this problem is not simply programming but it involves cognition, our spatio-temporal movements, and our awareness of the environment in which we work. Therefore this problem includes representation of the world, processes involved, and comes under multi-disciplinary Cognitive Work Analysis (CWA) and Human Work Interaction Design (HWID) frameworks [6]. The problem requires understanding of the relation between human and machines that we can study in a complex sociotechnical system such as control room of power, oil, and gas industries or particularly energy sector. Here our aim is to analyze the whole system not just human operators 
or machines in isolation but complete work settings so that individuals can act more effectively and preserve system safety and efficiency. We are analyzing work domain of the hydropower plant control room as shown in figure 2

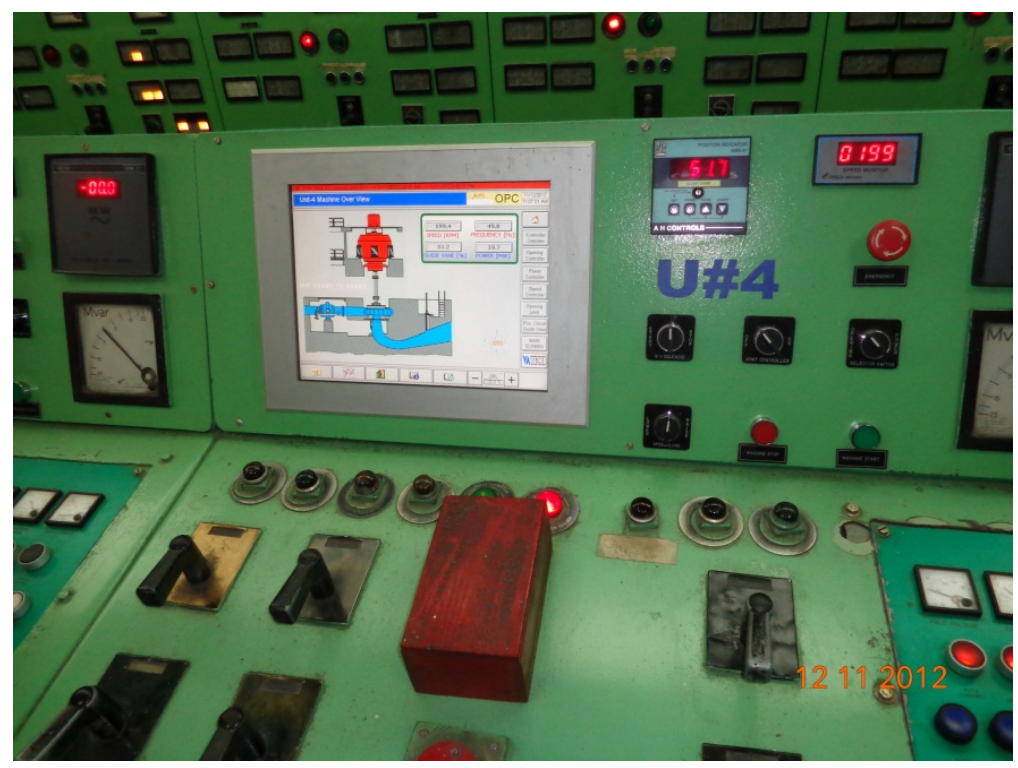

Fig. 2. Control Room Panel of a Hydropower Plant

\section{Human System Interfaces Based on Ecological Interface Design}

To study work environment and particular situation we are using CWA and HWID frameworks and focusing on guidelines related to Human System Interfaces (HSI). Embodied view provides a sharp contrast from the standard information-processing viewpoint, in which cognition is seen as a problem of recovering details of the pregiven outer world [2]. In this light, the mind is no longer seen as passively reflecting the outside world, but rather as an active constructor of its own reality. The mind thereby becomes a distributed entity, an emergent characteristic of the whole sensorycentral-motor neural system, existing in the elaborate network of interconnections that extend throughout the body. The philosophy of embodiment also stresses temporal, physical, and socio-cultural-technical situatedness. And, quite significantly, the embodied view in cognitive science allows for direct social and cultural interaction, which is crucial for understanding work situations.

In any power plant control room there are two objectives: first is to present to the operator components of plant and second is to minimize information or Cognitive overload on operator. To exhibit this, traditional display is shown in figure 2 and ecological display in figure 3 based on ecological interface design (EID) [9]. EID 
presents intangible abstract concepts visible and meaningful to operators [8]. For analyzing work situations in control room following questions are important:

- Objects representation and their meaning

- What makes us to acquire knowledge about the objects in the world, their specific relations, and properties

- How we extract information, its meaning

- Ontology of objects

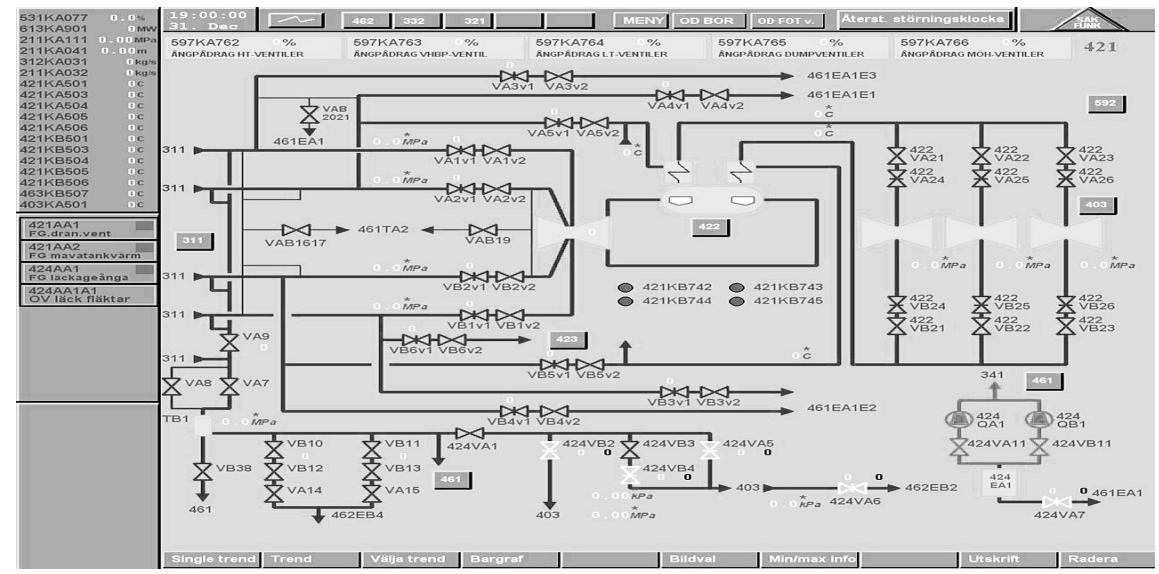

Fig. 3. A traditional display for the steam system [10]

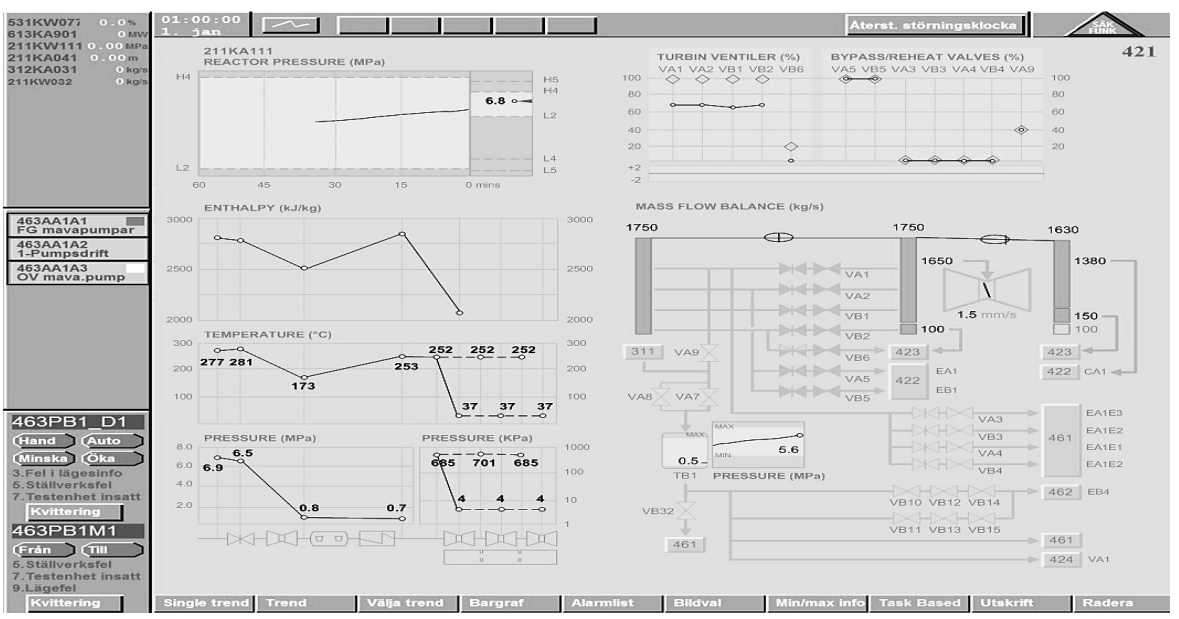

Fig. 4. An ecological display for the turbine system [10]

Ecological display clearly represents reactor pressure, enthalpy, temperature, pressure, and mass flow balance for better decision making. Through this work in progress, we would like to improve information displays, layout of system information, processes, and alarm system of a complex system such as power plant. Besides 
this study intend to find link between electricity distribution and control room status. These are larger unit of analysis and involve social-technical and cultural issues.

\section{$4 \quad$ Research Analysis and Discussion}

Hutchins tried to show that the cognitive science approach could be, with little modification, applied to a unit of analysis, which is larger than an individual. The unit of analysis here is a larger cognitive socio-technical system, such as an automated industrial setting (electricity distribution system [11], [12] power plant control room) [10], [13] and airline cockpit [14]. This approach is related to cognitive work analysis of studying processes in work environment. In both approaches, the question remains the same: what are the structures and processing of representations, which are internal to the system? To explain information-processing properties of individuals or larger systems, it is difficult to infer what is inside their mind [15] [16]. But for larger sociotechnical systems, it is possible to directly observe the different representations that are inside the system, despite being outside the brain of individual. The above objectives can be attained through analyzing the various contributions of the environment in which work activities take place. Such as representational media (e.g. instruments, displays, manuals, navigation charts), the interactions of individuals with each other and their interactive use of artifacts (computer systems). Simultaneously, how information necessary to cooperate is propagated through the system by representational states and across machines is analyzed.

CWA is a work-centered conceptual framework developed by Rasmussen, Pejtersen, and Goodstein. Through CWA designing of constraints based interfaces is possible and such interfaces support operators in dealing with uncertain events and proved to be useful not just usable interfaces [17].Through CWA \& HWID we analyzes the work people do, the tasks they perform, the decisions they make, their information behavior, and the context in which they perform their work [18]. CWA is a holistic approach and examines several dimensions: the environmental, organizational, social, activity, and individual. Therefore, we require a multi-disciplinary approach to apply concepts of CWA to study complex system [5].

In present research, we apply HWID framework for power plant control room panel interfaces to design the information system interaction and activities. As we live in the world, environment and interaction with others plays an important role. Thus both the paradigms find applications in various research projects and areas notably are studies of work domain analysis, robotics, autonomous agents, and interactive interfaces. These research directions will also be central for future developments of manmachine interaction, studying and enhancing the limits of information processing capacities of human and machine. These understandings result in better cooperation between human and computer that will enhance our capacities as supported by technology. Present research work explores the complex work environment to study cognition, cognitive tasks, and mental representations that will result in computational model of control room interactions and work setting for information handling based on CWA [19] \& HWID (as in fig. 5). Further application is using Abstraction 
Hierarchy method for the redesigning of the Control System Man-Machine Interface (MMI) of the Medium Tension Distribution Network of the Public Power Corporation of Greece [20].

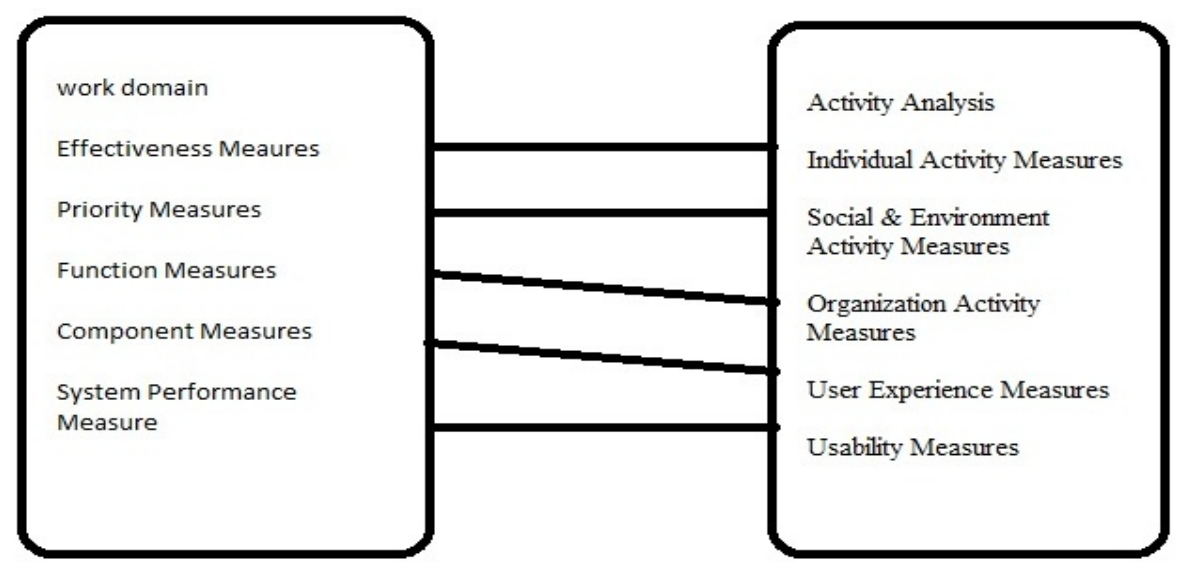

Fig. 5. Framework for Work - Activity Measure Analysis

\section{Conclusion}

This research provides understanding of cognition underlying human interactions with machines to improve design of both machines and work situations. We need interfaces and work situation, which reduces error and cognitive overload on human. Thus use of cognitive system engineering in the energy sector will helps us to analyze, model, design and evaluate effective human integration in complex socio-technical systems. The role of human operators in power plant control rooms is not only to control plant but also to meet market conditions and goals. With the advent of new Information Technology infrastructure we need to assess information requirements to manage control room that suits both human, machines, and economies.

Acknowledgements. First author would like to thank Prof. Torkil for helpful in writing and completing the paper. Also thankful to Dr. S. J. Chopra, Chancellor, and Dr. Parag Diwan, Vice-Chancellor, UPES for their encouragement and support.

\section{References}

1. Clark, A.: Being There: Putting Brain, Body and World Together Again. MIT Press, Cambridge (1997)

2. Varela, F.J., Thompson, E., Rosch, E.: The Embodied Mind. MIT Press, Cambridge (1992)

3. Brooks, R.A.: Intelligence Without Representation. Artificial Intelligence Journal (47), 139-159 (1991) 
4. Dautenhahn, K.: Embodiment and Interaction in Socially Intelligent Life-Like Agents. In: Nehaniv, C.L. (ed.) CMAA 1998. LNCS (LNAI), vol. 1562, pp. 102-142. Springer, Heidelberg (1999)

5. Fidel, R., Pejtersen, A.M.: From information behavior research to the design of information systems: the Cognitive Work Analysis framework. Information Research 10(1) (2004)

6. Clemmensen, T.: A Human Work Interaction Design (HWID) Case Study in EGovernment and Public Information Systems. International Journal of Public Information Systems (2011)

7. Smith, B.C.: On the Origin of Objects. MIT Press, Cambridge (1996)

8. Burns, C.M., Hajdukiewicz, J.R.: Ecological Interface Design. CRC Press, Florida (2004)

9. Memisevic, R., Sanderson, P.M., Choudhury, S., Wong, W.: Work domain analysis and ecological interface design for hydropower system monitoring and control. In: Jamshidi, M., Tunstel Jr., E., Anderson, G., et al. (eds.) Proceedings of the IEEE International Conference on Systems, Man and Cybernetics, October 10-12, pp. 3580-3587. IEEE, Big Island (2005)

10. Burns, C.M., Skraaning, G., Jamieson, G.A., Lau, N., Kwok, J., Welch, R., Andresen, G.: Evaluation of Ecological Interface Design for Nuclear Process Control: Situation Awareness Effects. Human Factors 50(4), 663-679 (2008)

11. Hay, S.L., Ault, G.W., Mcdonald, J.R.: Process of Simulating Novel Control Room Scenarios for Future Active Networks. In: 20th International Conference on Electricity Distribution, Prague, June 8-11 (2009)

12. Memisevic, R., Sanderson, P.M., Wong, W., Choudhury, S., Li, X.: Investigating HumanSystem Interaction with an Integrated Hydropower and Market System Simulator. IEEE Transaction on Power System 22(2) (May 2007)

13. Braseth, A.O., Nihlwing, C., Svengren, H., Veland, O., Hurlen, L., Kvalem, J.: Lessons Learned From Halden Project Research on Human System Interfaces. Nuclear Engineering and Technology 41(3) (April 2009)

14. Hutchins, E.: Cognition in the Wild. MIT Press, Cambridge (1995)

15. Garg, A.B.: Can Vision Provide Answers to Consciousness. In: International Conf. on Theoretical Neurobiology, NBRC, Manesar, Haryana, February 24-26 (2003)

16. Garg, A.B.: Design of Information System Interfaces: Using Human Computer Interaction and Cognitive System Engineering Paradigm. In: 2nd Uttarakhand Science Congress, Nainital, November 15-17 (2007)

17. Vicente, K.J.: Cognitive Work Analysis: Toward Safe, Productive, and Healthy ComputerBased Work. LEA, Mahwah (1999)

18. Sanderson, P.: Cognitive Work Analysis across the system life cycle: Achievement, challeneges, and prospects in aviation. In: Pfister, P., Edkins, G. (eds.) Aviation Resource Management, vol. 3. Ashgate, Aldershot (2003)

19. Jenkins, D.P., Solutions, S., Stanton, N.A., Salmon, P.M., Walker, G.H.: Cognitive Work Analysis: Coping with Complexity. Ashgate (2008)

20. Drivalou, S., Marmaras, N.: Tracing Interface Design solutions for an Electricity Distribution Network Control System Using the Abstraction Hierarchy. In: Proceedings of the XVth Triennial Congress of the IEA. The Ergonomics Society of Korea, Seoul (2003) 